\title{
DYNAMIC EMBRITTLEMENT IN ALLOY 718
}

\author{
J. A. Pfaendtner ${ }^{1}$ and C. J. McMahon, $\mathrm{Jr}^{2}$ \\ 1. General Electric Aircraft Engines, Cincinnati, $\mathrm{OH}$ \\ 2. Dept. of Materials Science and Engineering, \\ University of Pennsylvania, Philadelphia, PA
}

\begin{abstract}
The oxygen-induced intergranular cracking of alloy 718 under static loads has been found to be similar to that of sulfur-induced cracking in steels, tin-induced cracking in a Cu-Sn alloy, and oxygen-induced cracking in $\mathrm{Cu}-0.25 \% \mathrm{Be}$ and in $\mathrm{Ni}_{3} \mathrm{Al}$, all under static loads. These are all examples of a type of fracture called "dynamic embrittlement." This appears to be the same phenomenon as observed during cyclic loading of alloy 718 , especially with extended hold times, and it is considered that the cyclic nature of the loading is incidental to the cracking process.
\end{abstract}




\section{Introduction}

The fact that fatigue cracking in Ni-based superalloys is highly sensitive to the presence of oxygen is by now well known [1-7]. Cracking in air is intergranular and is accelerated by slow loading rates and extended hold times under a tensile stress. This problem has now been examined from a different perspective [8], and it has been shown that the same kind of cracking occurs during static loading. This implies that the intergranular fatigue cracking is fundamentally a time-dependent cracking problem that is not a direct consequence of cyclic loading.

This perspective has evolved from studies of stress-relief cracking in steels [9] and the similar type of cracking in a $\mathrm{Cu}-\mathrm{Sn}$ alloy [10]. In these cases intergranular cracking occurs at elevated temperatures in vacuum as a result of stress-driven inward diffusion of embrittling elements adsorbed on a surface. These elements, sulfur in the steel and tin in the Cu-Sn, segregate to the surface from the bulk alloy. The process is analogous to the Hull-Rimmer [11] mechanism of diffusive creep-cavity growth whereby atoms on the surface of a cavity are induced to diffuse into the surrounding grain boundary by the gradient in chemical potential imposed by a tensile stress. That is, the stress does work when atoms from the surface of the cavity, some of which are embrittling species, are "plated out" in the surrounding boundary. If the stress is high enough, the boundary peels open at rates on the order of $10^{-6} \mathrm{~m} / \mathrm{sec}$. This process has been called "dynamic embrittlement" $[9,12]$, because the embrittlement takes place as a result of the application of stress and as the crack grows.

Recognizing that this phenomenon should occur regardless of the source of the surfaceadsorbed embrittling elements, experiments were carried out at elevated temperatures in various pressures of oxygen on a $\mathrm{Cu}-0.25 \% \mathrm{Be}$ alloy $[13,14]$ and on alloy $718[8,14]$. Using the same fixed-displacement test in all cases, it was found that the cracking in the $\mathrm{Cu}-\mathrm{Be}$ and in alloy 718 was essentially similar to that in the steel and $\mathrm{Cu}-\mathrm{Sn}$ alloy. Therefore, the position can be taken that this is a generic form of slow brittle fracture. The work on alloy 718 [8] is reviewed here.

\section{Cracking under Fixed Displacement}

The specimens were in the form of notched bars loaded at fixed displacement in pure bending in a vacuum chamber. As cracking occurred, the load relaxed, and the cracking rate could be calculated from knowledge of the dependence of the specimen compliance on the crack length. Examples of the load relaxation curves for a $\mathrm{MnMoNiCr}$ steel and for alloy 718 are shown in Fig. 1 . The steel had been heated to $1250^{\circ} \mathrm{C}$ and cooled fairly rapidly to allow sulfides to dissolve and then re-precipitate along austenite grain boundaries. The alloy $718 \mathrm{had}$ been forged and then given the following heat treatment: $1040^{\circ} \mathrm{C}$ for $1 \mathrm{~h}$ and oil quench, then $718^{\circ} \mathrm{C}$ for $12 \mathrm{~h}$, furnace cool to $620^{\circ} \mathrm{C}$ and hold $12 \mathrm{~h}$. The average grain diameter was 75 to $100 \mu \mathrm{m}$. . Examples of crack velocity vs. stress intensity in alloy 718 at different oxygen pressures are shown in Fig. 2.

An illustration of how responsive the cracking rate was to a change in oxygen pressure is shown in Fig. 3. The cracking stopped immediately when the oxygen was removed from the test chamber, and it began immediately when the oxygen was re-introduced a few minutes later. This indicates that the effect of the oxygen must have occurred very close to the crack tip.

The crack-growth rate dropped by almost three orders of magnitude when the oxygen pressure was reduced below $0.1 \mathrm{~Pa}$, as shown in Fig. 4. This is very similar to what was observed in cyclic loading of alloy 718 [16]. 


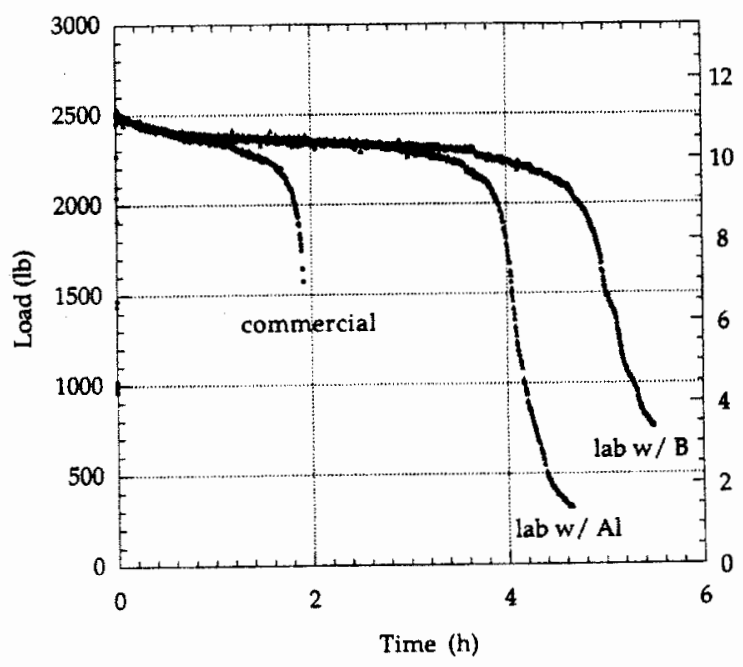

(a)

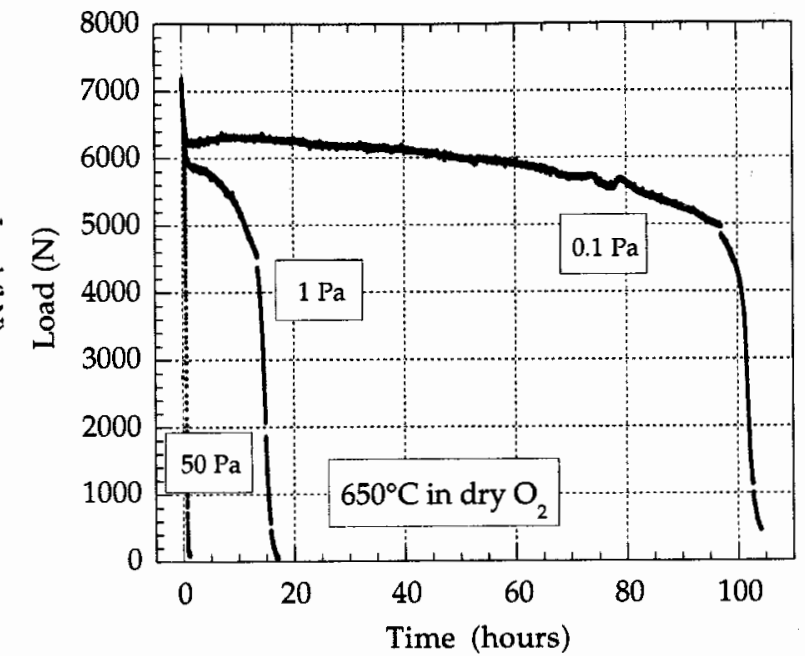

(b)

Fig. 1. Examples of load-relaxation in constant-displacement tests that results from dynamicembrittlement-type cracking in (a) MnMoNiCr steels in vacuum at $550^{\circ} \mathrm{C} \mathrm{[15]} \mathrm{and} \mathrm{(b)} \mathrm{alloy} 718$ in various pressures of oxygen.

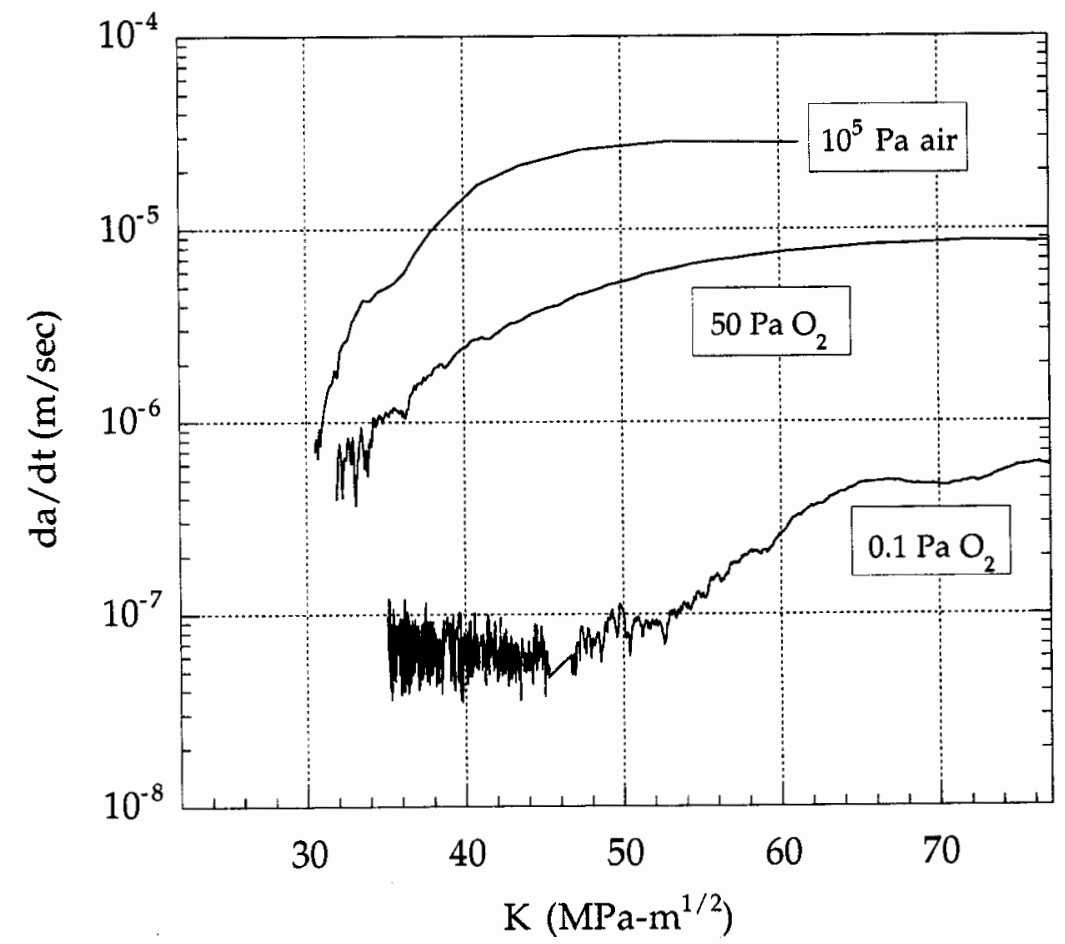

Fig. 2 Crack velocity vs. stress intensity curves derived from the load-relaxation curves and a compliance-calibration curve for alloy 718 at $650^{\circ} \mathrm{C}$ in various pressures of oxygen. 


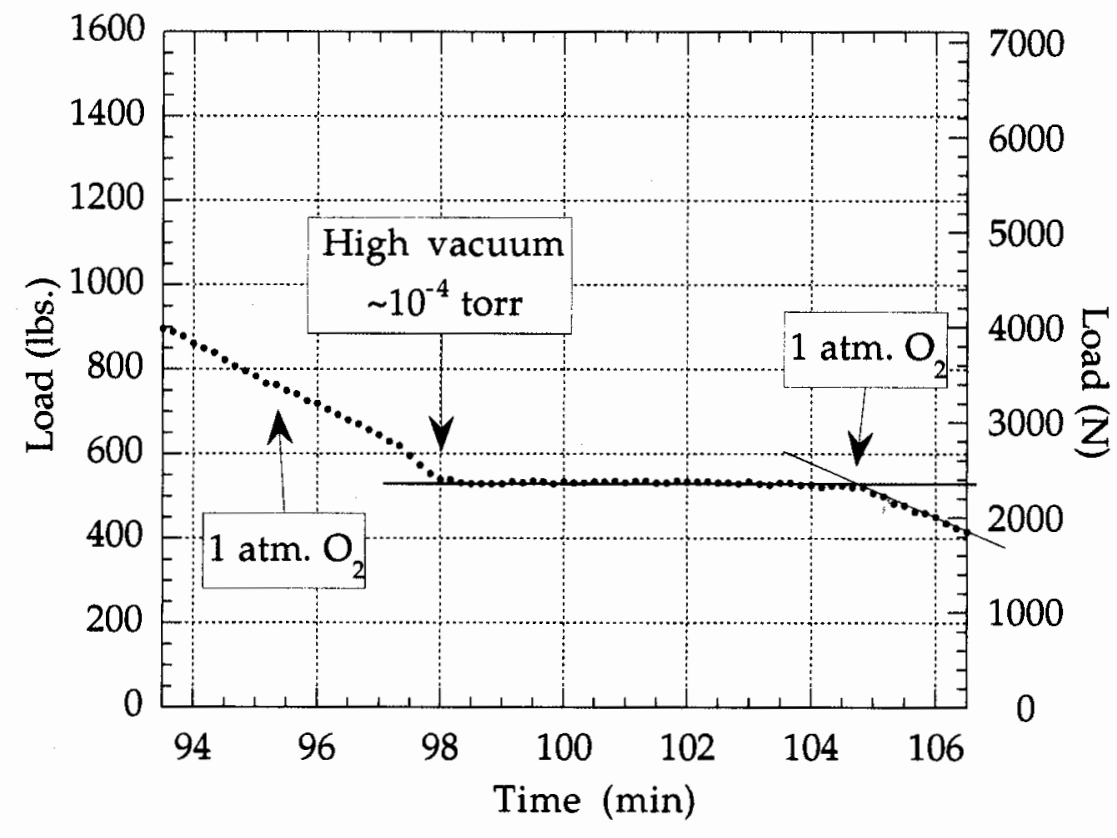

Fig. 3 Part of a load-relaxation curve for alloy 718 at $650^{\circ} \mathrm{C}$ showing the immediate response to the removal and re-introduction of oxygen in the test chamber.

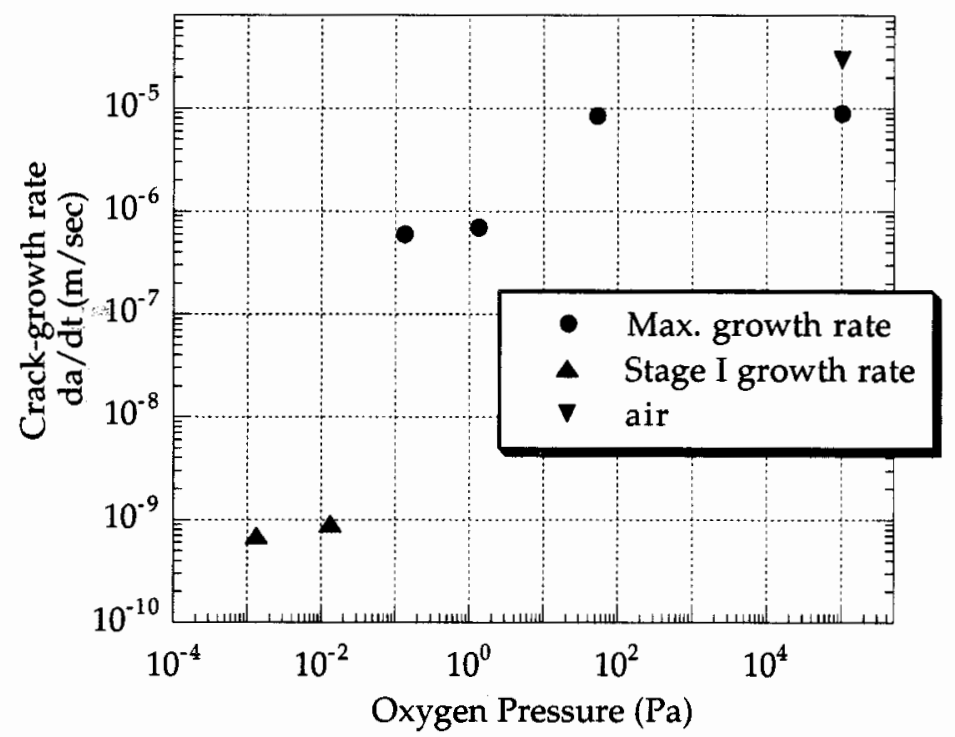

Fig. 4 The effect of a reduction in oxygen pressure on the maximum rate of crack growth in alloy 718 at $650^{\circ} \mathrm{C}$

Along with the precipitous drop in crack-growth rate came a change in the fracture mode. In the higher-pressure range the cracking was fairly smooth and had the appearance of decohesion with fine particles of oxide formed after the crack had passed, as shown in Fig. 5a. However, in the lower pressure range, the appearance was quite different, as shown in Fig. 5b. Here, the crack had clearly moved forward in small steps, and the time interval between steps was 
sufficient for the formation of a string of oxides along the crack front and for blunting of the crack tip.

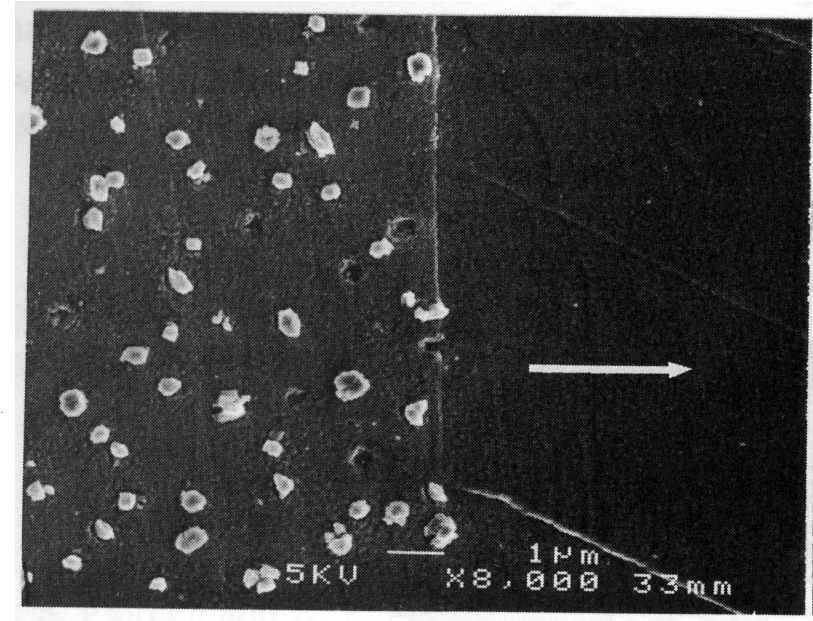

(a)

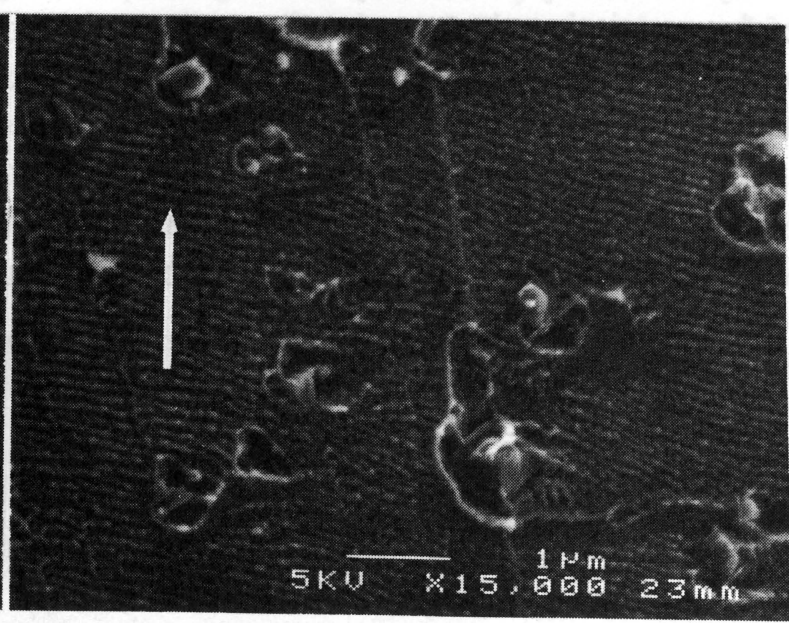

(b)

Fig. 5 Fracture appearance resulting from cracking in (a) the high-pressure regime and (b) the low pressure regime shown in Fig. 4. The arrows indicate the direction of crack growth.

The interpretation of these crack surfaces is as follows: At the higher oxygen pressures the crack remained sharp and propagated in rapid jumps. Whereas in a $\mathrm{Cu}-\mathrm{Sn}$ bicrystal the crack growth was continuous [17], it has been found to be discontinuous in all the cases of polycrystals studied so far $[9,10,13,14]$. This occurs because the rate of crack advance depends on the rate of diffusion of the embrittling element into the grain boundary ahead of the crack. Because of this, the crack advances at different rates along the crack front, so that when one region moves forward, the local stress is relaxed and the load is carried by the non-advancing regions. When the latter stretch by creep, the local stress again rises and the crack advances. This process is then repeated over and over. Thus, cracking in polycrystals is discontinuous because of the constraint of non-cracking regions. It would be expected to be continuous in a bicrystal. In the low-pressure regime, the rate of delivery of oxygen to the crack tip is too slow to permit the growth of the crack from its sharp tip. Oxygen atoms diffuse away from the tip, and the tip blunts. The oxygen atoms then build up in the region of maximum stress ahead of the tip, and when the concentration is large enough, the boundary cracks back to the tip, and the process is repeated.

The fact that the cracking of a polycrystal is constrained by non-cracking regions of the specimen at any instant in time has two consequences. First, the applied stress intensity during the apparent $\mathrm{K}$-independent part of the velocity vs. K curve (Fig. 2) is much higher than the local $\mathrm{K}$ at the locations where the crack is advancing at any instant. It was found that cracking can occur in the alloy 718 at stress intensities below $10 \mathrm{MPa} \sqrt{\mathrm{m}}$. The $\mathrm{Cu}-\mathrm{Sn}$ bicrystals [17] cracked at stress intensities below $3 \mathrm{MPa} \sqrt{ }$. Secondly, the temperature dependence of the cracking was closer to that of self-diffusion in nickel than to oxygen diffusion in nickel grain boundaries [14]. This comes from the fact that the overall cracking rate is controlled by powerlaw creep in the non-cracking regions. Because of this behavior, it is clear that the details of the mechanisms of this cracking cannot be determined in polycrystalline specimens, but that bicrystals will be required.

Some insights about the process of crack growth can be gained from observations of the tips of cracks, the growth of which was interrupted by unloading of the specimen, followed by lowtemperature fracture to expose the crack surface. A typical example is shown in Fig. 6. There is 
a strip of decohered grain boundary that has relatively little oxide lying between the more heavily oxidized crack surface and the low-temperature fracture. This strip, which is about $1 \mu \mathrm{m}$ wide, presumably formed by crack growth during the unloading, as the crack was closing and thereby restricting the access of oxygen to the crack tip. From Fig. 2, it can be seen that the overall crack velocity would have been about $5 \times 10^{-5} \mathrm{~m} / \mathrm{sec}$ at this oxygen pressure, so it is reasonable to conclude that the local crack velocity was of the order of $10^{-5} \mathrm{~m} / \mathrm{sec}$. Thus, the $1 \mu \mathrm{m}$ strip would have formed in about $0.1 \mathrm{sec}$, and this is consistent with its having formed during unloading. The main point to be made here is that the oxide formation occurs after the crack has passed, so the process of cracking cannot be the result of the oxide formation.

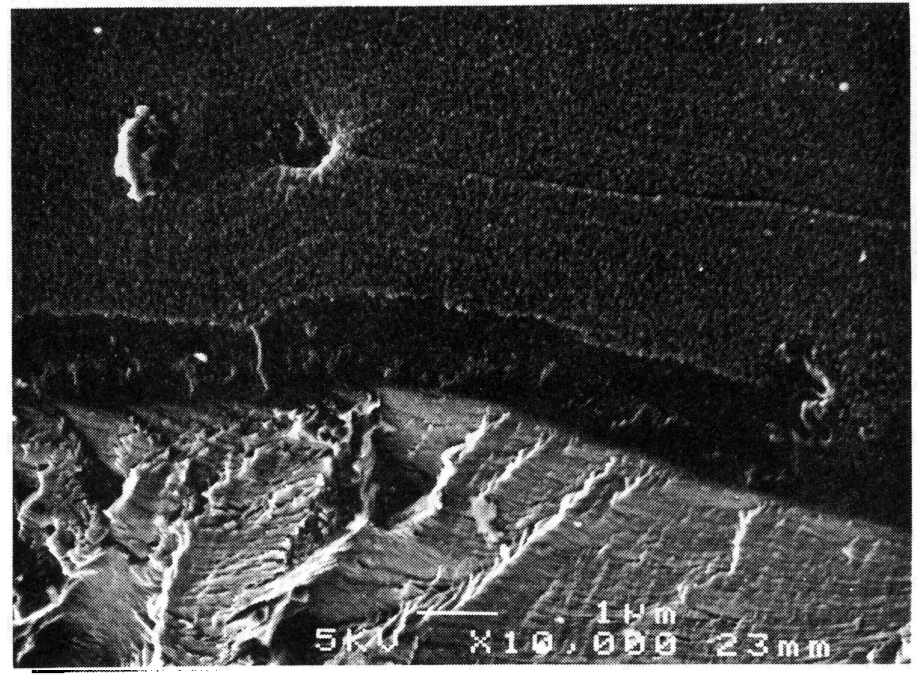

Fig. 6 The tip region of a crack that was growing in alloy 718 in $1 \mathrm{~atm}$ oxygen at $650^{\circ} \mathrm{C}$, the growth of which was interrupted by unloading the specimen. The lower part of the micrograph represents post-test impact fracture at room temperature.

A second point concerning Fig. 6 is that close examination of the original micrograph revealed that the lightly oxidized strip appeared to represent 5 jumps of the crack front, judging from the faint lines of oxide in the strip. This would mean that each jump took about $0.02 \mathrm{sec}$, or that the crack was proceeding at a rate of 50 jumps per second.

\section{Possible Remedies for Dynamic Embrittlement}

The cracking involves diffusive penetration of grain boundaries ahead of a sharp crack tip, as demonstrated by experiments on bicrystals of $\mathrm{Cu}-\mathrm{Sn}$ [17]. Thus, having an innocuous element segregated to the grain boundaries that would act to inhibit grain-boundary diffusion should also inhibit crack growth. This kind of remedy has been applied to the problem of oxygen-induced cracking of the $\mathrm{Cu}-0.25 \% \mathrm{Be}$ alloy during hot working. The problem was eliminated [18] by the addition of $400 \mathrm{ppm}$ zirconium to the alloy. For such a small addition to have an effect on a grain-boundary-cracking problem, the zirconium atoms would have to be segregated to the grain boundaries of the alloy. This is reasonable, because the zirconium atom is significantly larger than the copper atom. Whether the zirconium also acts to scavenge oxygen, in addition to blocking diffusion, is a matter for further study. This type of remedy could presumably be applied to nickel-base alloys, and it may in fact already be acting in particular crack-resistant cases without being explicitly recognized.

Another potential remedy would be to apply the process of so-called "grain-boundary engineering" to nickel-base alloys in order to increase the population of special boundaries. This has been applied to various alloys to improve their resistance to intergranular stress corrosion 
and creep rupture; for example see refs. 19-21. The reported definition of a special boundary is one having a misorientation between the constituent grains such that the density of coincidence sites in the two lattices is greater than one in 29 lattice points. Such a boundary would be said to have a $\Sigma$ value of less than 29 . There is every reason to believe that the GBE approach would work also for dynamic embrittlement, because it is so sensitive to grain-boundary structure $[8,9,14,17]$. This is an area that very much deserves further study.

\section{Acknowledgements}

The work reviewed here was supported by the National Science Foundation under grants no. DMR 96-34718 and CMS 95-03980.

\section{References}

1. C.J. McMahon Jr. and L.F. Coffin Jr., Met. Trans. 1 (1970) 3443.

2. T. Ericsson, Canadian Metallurgical Quarterly 18 (1979) 177.

3. S. Floreen and R. Raj, Flow and Fracture at Elevated Temperatures, Ed. R. Raj, ASM, Metals Park, OH, (1985).

4. P.N. Chaku and C.J. McMahon Jr., Met. Trans. 5, 441 (1974).

5. E. Aghion, M. Bamberger, and A. Berkovits, Matl. Sci. \& Eng. A147, (1991) 181.

6. S. Floreen and R.H. Kane, Met. Trans. 10A (1979) 1745.

7. S. Floreen, Met. Trans. 6A, 1741 (1975).

8. J. A. Pfaendtner and C. J. McMahon, Jr, Acta Mater. 2001, in press.

9. D. Bika and C.J. McMahon Jr., Acta Metall. 43 (1995) 1909.

10. E. V. Barrera, M. Menyhard, D. Bika, B. Rothman, and C. J. McMahon Jr., Scripta Metall., $27(1992) 205$.

11. D. Hull and D. E. Rimmer, Philos. Mag.. 4 (1959) 673.

12. C.T. Liu and C.L. White, Acta Metall. 35 (1987) 643.

13. R. C. Muthiah, PhD Thesis, University of Pennsylvania, 1997.

14. J. A. Pfaendtner, PhD Thesis, University of Pennsylvania, 1998.

15. S. Ishikawa, J. A. Pfaendtner, and C. J. McMahon, Jr., Mat. Sci. Eng. A272 (1999) 16.

16. R. Molins, G. Hochstetter, J.C. Chassaigne, and E. Andrieu, Acta Metall. 45 (1997) 663.

17. R. C. Muthiah, J. A. Pfaendtner, S. Ishikawa, and C. J. McMahon, Jr., Acta Mater. 47 (1999) 2797.

18. A. Guha, Brush-Wellman Inc., private communication, 1993.

19. G. Palumbo, E. M. Lehockey, and P. Lin, JOM 50(2) (1998) 40.

20. G. S. Was, V. Thaveeprungsriporn, and D. C. Crawford, JOM 50(2) (1998) 44.

21. M. Kumar, W. E. King, and A. J. Schwartz, Acta Mater, 48 (2000) 2081. 